\title{
INTERESTING TIMES
}

\author{
Inaugural address by the ICCA President
}

\section{T. Anthony Marsland}

With the $7^{\text {th }}$ WCCC behind us, we can look forward to another 3 years of exciting growth in computer chess. It is too much to hope that the reigning world chess champion will lose even a casual game against a computer in these three years, but I am sure it will not be for want of trying; and it is too early to assert that by the year 2020 we will no longer find a person who can win matches against the best computer program. It is also not clear whether the champion machine will be a superfast single processor, or some form of multi-computer, especially since there is still much to learn about extending and abbreviating game-tree searches. Thus we are fortunate to be here for these interesting times!

Because the previous World Computer-Chess Champion (Deep Thought) chose not to defend its title, the Madrid event ensured that a new champion would emerge from out of a crowd of very strong contestants. Likewise there has been a change in the ICCA Board. In particular, Jonathan Schaeffer has stepped down as Secretary/Treasurer, thus causing new blood to be injected into the organization. During Jonathan's 6-year tenure a careful account of the ICCA's expenditures has been kept, and with the help of new sources of income we became solvent. The ICCA board owes Jonathan its deepest gratitude for his conscientious efforts, and we look forward to having him as an Associate Editor of the Journal. The ICCA board also welcomes the new Treasurer, Don Beal (from Queen Mary and Westfield College of the University of London) with unrestrained enthusiasm.

After six years as President, David Levy felt it time to shed some of the burdens he has been carrying. However, in his new role as Vice-President he has agreed to continue with the unenviable task of seeking out sites and sponsors for the annual World Micro CCC. Until now, these events have been held primarily in Europe, leading to an emergence from there of a variety of micro-based chess programs. Perhaps in time David's role will change further - but he remains a key person, dedicated to the support of the ICCA's ideals of expanding interest in computer chess and helping chess programmers become established in their discipline. He has served us well and I hope you will add your voices to mine with a sincere vote of thanks.

What then does the future hold? First the ICCA Journal will continue to publish both recent research and a miscellany of reports of interest to chess-players with a knowledge of computing. Second we will continue to recruit new subscribers to the ICCA Journal. Because the Journal provides the best outlet for new ideas on computer chess, the subscription rate is being kept within a student's budget. However we must simultaneously expand our circulation to include more City and University libraries. Here you, the patient reader, can help not only by encouraging your local library to request subscription details (and perhaps a free sample copy of the Journal), but also by continuing to participate in our computer-chess events. An increase in library subscriptions will provide us with greater stability, as indeed will a quick renewal of your personal subscription which falls due with this issue! Information on how to subscribe is given on the closing page of the Journal.

Finally, on behalf of the ICCA Board, I wish you all a Happy and Prosperous New Year and we look forward to greeting you individually one day, and exchanging experiences on developing good computer-chess programs. 